\title{
Characteristics of coronary arterial lesions in patients with coronary heart disease and hypertension
}

\author{
Jing-Xia Zhang, Hong-Zhi Dong, Bing-Wei Chen, Hong-Liang Cong and Jing Xu*
}

\begin{tabular}{l}
\hline *Correspondence: \\
jingxu86@sina.cn \\
Department of Cardiology, \\
Tianjin Chest Hospital, \\
Jizhao Road, Jinnan District, \\
Tianjin 300222, China
\end{tabular}

${ }^{*}$ Correspondence: jingxu86@sina.cn Tianjin Chest Hospital, Tianjin 300222, China

\begin{abstract}
Objective: The aim of this study was to investigate the correlations between risk factors such as hypertension and the complex degrees of coronary arterial lesions (CAL).

Methods: We selected 462 patients with coronary heart disease (CHD) with confirmed the stenosis $(\geq 50 \%)$ in at least one major coronary artery on coronary angiography and divided them into the "CHD with hypertension" group (CHD-HT, $n=306)$ and the CHD group $(n=156)$. The characteristics of CAL and the occurrence of 2-year postoperative major adverse cardiac cerebrovascular events (MACCE) in the two groups were observed.

Results: The mean SYNTAX scores (SS) was higher in the CHD-HT group than in the CHD group $(P<0.05)$. The proportions of complex, calcified, and diffused long lesions in the $\mathrm{PCl}$ patients' target vascular lesions, as well as the total MACCE incidence, were significantly higher in the CHD-HT group than in the CHD group $(P<0.05)$. Logistic multifactor regression analysis showed that age, male sex, hypertension, diabetes, hyperlipidemia, and previous history of myocardial infarction were positively correlated with the SS $(P<0.05)$.
\end{abstract}

Conclusions: The patients with CHD-HT exhibited complicated and diffused CAL, and arterial hypertension can be considered as a risk factor for the complexity of coronary lesions in patients with ischemic heart disease.

Keywords: Hypertension, Coronary heart disease, Risk factor, Interventional treatment

\section{Background}

Epidemiological studies have confirmed the close etiological relationship between the risks of hypertension and coronary heart disease (CHD) (Lawes et al. 2002; McInnes 1995). Hypertension has been proven to be a risk factor of CHD, with significant and independent effects. Hypertension and CHD could jointly promote the occurrence and development of coronary atherosclerosis through mechanisms such as influencing the shearing force of blood flow, the coronary endothelial functions, the permeability of the vascular wall, the adhesive characteristic of platelets, and vascular wall remodeling (Figueiredo et al. 2012; Sipahi et al. 2006; Sudano et al. 2011). In addition, hypertension was demonstrated to be an independent risk factor that could impact cardiovascular death events and prognosis (Frohlich and Susic 2007; Turnbull 2003).

(c) 2016 The Author(s). This article is distributed under the terms of the Creative Commons Attribution 4.0 International License (http://creativecommons.org/licenses/by/4.0/), which permits unrestricted use, distribution, and reproduction in any medium, provided you give appropriate credit to the original author(s) and the source, provide a link to the Creative Commons license, and indicate if changes were made. 
Because of the lack of better objective indicators for evaluating the coronary complexities, previous studies about the correlations between risk factors such as the hypertension and the severity and complexity of coronary arterial lesions (CAL) were few. The SYNTAX score (SS) is a lesion-based angiographic scoring system that was developed to quantify the number, complexity, and location of lesions in patients undergoing percutaneous coronary intervention (PCI). Higher SS are related to more-complex diseases. Therefore, patients undergoing PCI with high SSs are likely to have worse prognosis. The SS is based on anatomical features of CAL and can be used to quantitatively evaluate the complexity of CAL according to anatomical features such as lesion location, severity, bifurcation, and calcification. Although its clinical applications have some limitations such as its inability to determine the characteristics of plaques and coronary flow reserve, a large number of studies have confirmed that the SS has strong clinical practicality when used as a risk assessment tool for coronary revascularization (Farooq et al. 2014; Head et al. 2014; Mohr et al. 2013).

The aim of our study was to analyze the relationships between risk factors (e.g., hypertension, aging, diabetes mellitus, and hypercholestirol) and the complexity of CAL in order to investigate the roles of hypertension and other risk factors in the progression of CHD.

\section{Methods}

\section{Study population}

We selected 462 CHD patients who were admitted at the Tianjin Chest Hospital between January 2010 and June 2010 in order to undergo coronary angiography and had confirmed stenosis ( $\geq 50 \%$ ) in at least one major coronary artery. The subjects were divided into two groups according to the presence or absence of hypertension as follows: the "CHD combined with hypertension" group (CHD-HT; group A; $\mathrm{n}=306$ patients; 164 men and 142 women; mean age, $69.6 \pm 10.6$ years) and the CHD group (group B; $\mathrm{n}=156$ cases; 108 men and 48 women; mean age, $69.5 \pm 10.6$ years). Patients with secondary hypertension, rheumatic heart disease, cardiomyopathy, pulmonary heart disease, and permanent pacemaker placement were excluded. This study was conducted in accordance with the declaration of Helsinki. This study was conducted with approval from the Ethics Committee of Tianjin Chest Hospital. Written informed consent was obtained from all participants.

\section{Sample collection}

Samples of peripheral venous blood were drawn from the antecubital vein at admission. Plasma triglyceride, low-density lipoprotein (LDL), high-density lipoprotein, glucose, and creatinine concentrations were measured by using an automated chemistry analyzer (Abbott Aeroset, Minnesota, USA) by using commercial kits (Roche Diagnostics Ltd., Germany).

\section{SS and angiographic analysis}

All of the patients underwent selective coronary angiography by using the Judkins technique, among whom 304 received PCI. The patients were given the standard treatment after hospital discharge. Follow-up through telephone, clinic visit, or angiography was 
performed from January 2012 to June 2012. CAL that led to $\geq 50 \%$ diameter stenosis in vessels $\geq 1.5 \mathrm{~mm}$ were scored separately. The cumulative SS, which was prospectively calculated by using the SS algorithm on the baseline diagnostic angiogram, was then calculated by adding the scores (Iqbal et al. 2014; Serruys et al. 2009). Two experienced interventional cardiologists blindly analyzed the SS, and the opinion of a third analyst was obtained. In cases of disagreement, the final judgment was made by consensus. The final score was calculated from the individual lesion scores by the analysts, who were blinded to the procedural data and clinical outcomes.

\section{Diagnostic criteria}

In the "Chinese Hypertension Prevention Guide (2010)," hypertension is defined the intake of any antihypertensive drug, a systolic blood pressure $\geq 140 \mathrm{~mm} \mathrm{Hg}$ and/or a diastolic blood pressure $\geq 90 \mathrm{~mm} \mathrm{Hg}$. If a patient had a history of hypertension and was currently taking antihypertensive drugs, although the present blood pressures did not reach the aforementioned levels, the patient could also be diagnosed with hypertension. Hyperlipidemia is defined in the "China Adult Dyslipidemia Prevention Guide (2007)" according to the characteristics and actual situations of the study populations, under normal diet, with a serum total cholesterol $\geq 5.72 \mathrm{mmol} / \mathrm{L}$, and associated with or without a serum triglyceride level $\geq 1.70 \mathrm{mmol} / \mathrm{L}$. Diabetes is referred to in the "Chinese Type 2 Diabetes Prevention Guide (2010)" as a random (anytime of the day) blood glucose level of $11.1 \mathrm{mmol} / \mathrm{L}$, a fasting (for at least $8 \mathrm{~h}$ ) blood glucose level $\geq 7.0 \mathrm{mmol} / \mathrm{L}$, or 2 -h glucose level $\geq 11.1 \mathrm{mmol} / \mathrm{L}$ in a glucose tolerance test. The above-mentioned indicators should be confirmed by repeated monitoring in a different day. Smoking was defined if the subject had continuously or accumulatively smoked for 6 months or more.

\section{Definition of clinical events}

Major adverse cardiac cerebrovascular events (MACCE) include nonfatal acute myocardial infarction (AMI), sudden cardiac death, revascularization, and ischemic or hemorrhagic stroke. Coronary angiographic restenosis was divided into in-stent restenosis and in-segment restenosis. In-stent restenosis refers to an inner diameter stenosis $>50 \%$ (quantitative coronary angiography), whereas in-segment restenosis refers to stenosis ( $>50 \%$ ) occurring at the vessel segment within the 5-mm border of the stent. Readmission was defined as rehospitalized in our hospital or other hospitals because of angina pectoris, heart failure, and revascularization.

\section{Statistical methods}

The SPSS17.0 statistical package was used for the statistical analysis. The counting data were expressed as percentages and analyzed by using the $\chi^{2}$ test. The measurement data were expressed as mean \pm standard deviation $(\bar{x} \pm \mathrm{s})$ values. The $t$ test was used to compare the mean values between the two groups, and the Kaplan-Meier method (log-rank test) was used to compare the event-free survival rate between the two groups, for which survival curves were drawn. The logistic regression model was used in the multivariate analysis, with a $P<0.05$ considered as statistically significant. With regard to the evaluated parameters, the values distributed were according to a normal distribution. 


\section{Results}

\section{Baseline characteristics}

The proportion of patients with a family history of CHD and/or hypertension was higher in the CHD-HT group than in the CHD group $(P<0.05)$. The proportion of males was higher in the CHD group than in the CHD-HT group $(P<0.05)$. Meanwhile, differences in the prevalences of diabetes, dyslipidemia, history of old myocardial infarction, smoking history, cardiac dysfunction, estimated glomerular filtration rate, and low-density lipoprotein and cholesterol levels were not statistically significant between the two groups (Table 1).

\section{CAL characteristics}

The ratios of single-vessel lesion, two-vessel lesion, three-vessel lesion, and left main stem lesion showed no statistically significant differences between the two groups. The mean SS and the proportions of patients with complex lesions, calcified lesions, and diffused long lesions were higher in the CHD-HT group than in the CHD group $(P<0.05)$. The PCI surgery rate did not statistically significantly differ between the two groups. The

Table 1 Basic information of the two groups

\begin{tabular}{|c|c|c|c|c|c|c|c|c|c|c|}
\hline \multirow[t]{2}{*}{ Group } & \multicolumn{8}{|c|}{ Disease type [n (\%)] } & \multirow{2}{*}{$\begin{array}{l}\text { Cardiac dysfunction } \\
\text { level III-IV [n(\%)] }\end{array}$} & \multirow[t]{2}{*}{ LVEF (\%) } \\
\hline & SAP & \multicolumn{2}{|l|}{ UAP } & \multicolumn{2}{|c|}{ STEMI } & \multicolumn{2}{|c|}{ NSTEMI } & UACHD & & \\
\hline$A(n=306)$ & $20(6.5)$ & \multicolumn{2}{|c|}{$180(58.8)$} & \multicolumn{2}{|c|}{$58(19.0)$} & \multicolumn{2}{|c|}{$18(5.9)$} & $30(9.8)$ & $38(12.4)$ & $59.91 \pm 8.63$ \\
\hline $\mathrm{B}(n=156)$ & \multirow[t]{2}{*}{$10(6.4)$} & \multirow{2}{*}{\multicolumn{2}{|c|}{$90(57.7)$}} & \multirow{2}{*}{\multicolumn{2}{|c|}{$42(26.9)$}} & \multirow{2}{*}{\multicolumn{2}{|c|}{$8(5.1)$}} & \multirow[t]{2}{*}{$6(3.8)$} & $16(10.3)$ & $60.32 \pm 9.39$ \\
\hline$t / x^{2}$ & & & & & & & & & 1.681 & 1.854 \\
\hline \multirow[t]{2}{*}{ Group } & \multicolumn{5}{|c|}{ Previous history [n (\%)] } & \multirow{2}{*}{\multicolumn{3}{|c|}{ LDL-C (mmol/L) }} & \multirow{2}{*}{$\begin{array}{l}\text { Fasting blood glucose } \\
(\mathrm{mmol} / \mathrm{L})\end{array}$} & \multirow{2}{*}{$\begin{array}{l}\text { eGFR }[\mathrm{ml} / \\
\left.\left(\min 1.73 \mathrm{~m}^{2}\right)\right]\end{array}$} \\
\hline & MI & $\begin{array}{l}\text { Previ- } \\
\text { ous } \\
\text { PCI }\end{array}$ & \multicolumn{3}{|c|}{$\begin{array}{l}\text { Old cerebral } \\
\text { infarction }\end{array}$} & & & & & \\
\hline$A(n=306)$ & $26(8.5)$ & $12(3.9)$ & \multicolumn{3}{|c|}{$42(13.7)$} & \multicolumn{3}{|c|}{$2.73 \pm 1.07$} & $6.25 \pm 1.86$ & $92.37 \pm 19.38$ \\
\hline $\mathrm{B}(n=156)$ & $6(3.8)$ & $6(3.8)$ & $12(7$ & 7.7) & & 2.68 & $8 \pm 1.1$ & & $27 \pm 2.01$ & $92.20 \pm 20.29$ \\
\hline$t / x^{2}$ & 3.466 & 0.002 & 3.64 & & & 0.5 & 57 & & 88 & 0.279 \\
\hline Group & Age & Male & [n $(\%$ & $\%)]$ & Other & com & nplicati & ns [n(\%)] & Family history [(\%)] & Smoking [n(\%)] \\
\hline & & & & & Diabe & ics & Hype & ipidemia & & \\
\hline$A(n=306)$ & $69.6 \pm 10$ & 6164 & 53.6) & & $82(26$. & & $124(4$ & & $94(30.7)$ & $122(39.9)$ \\
\hline$B(n=156)$ & $69.5 \pm 10$ & 6108( & $69.2)^{a}$ & & $34(21$. & & $62(39$ & & $24(15.4)^{a}$ & $68(43.6)$ \\
\hline$t / x^{2}$ & 0.307 & 8.265 & & & 2.302 & & 0.031 & & 14.439 & 0.591 \\
\hline Group & blo & ood pres & sure I & level & & & Medica & ions & & \\
\hline & & & & & & & Statin & & El or ARB & i-platelet agents \\
\hline$A(n=306)$ & 149 & $9.3 \pm 21$ & & & & & $65(21.2$ & & $2(36.6)$ & 55.2) \\
\hline$B(n=156)$ & 129 & $9.0 \pm 12$ & & & & & $31(19.8$ & & $(7.1)^{\mathrm{a}}$ & 49.4) \\
\hline$t / x^{2}$ & 11. & 039 & & & & & 0.118 & & 185 & \\
\hline
\end{tabular}

A: CHD-H group; $\mathrm{B}$ : CHD group

$S A P$ stable angina pectoris, UAP unstable angina pectoris, UACHD untypical or asymptomatic $\mathrm{CHD}, \mathrm{OMI}$ old myocardial infarction, STEMI acute ST-elevated myocardial infarction, NSTEMI non-ST-elevation acute myocardial infarction, LVEF left ventricular ejection fraction, eGFR estimated glomerular filtration rate, $L D L-C$ low-density lipoprotein cholesterol, $P C I$ percutaneous coronary within intervention

Compared with group $A,{ }^{a} P<0.01$ 
mean number patients with coronary stenting was higher in the CHD-HT group than in the CHD group $(P<0.05$, Table 2$)$.

\section{Two-year follow-up results}

Among the 304 patients who had successful PCI surgeries, 290 (95.4 \%) were followed up through telephone calls, 14 (4.6\%) were lost to follow-up, 88 (30.3\%) were followed up through clinic visits, and 34 (11.7 \%) were followed up by using angiography. Among the angiographic follow-up cases, 32 patients were followed up by performing coronary angiography within 2 years of $\mathrm{PCI}$ because of symptom recurrence and two agreed to undergo follow up with coronary angiography. Although the incidence rates of cardiac death, nonfatal myocardial infarction, re-revascularization, and stroke did not statistically significant differ between the two groups, the overall MACCE incidence was significantly higher in the CHD-HT group than in the CHD group $(P<0.05)$. The CHD-HT group had 16 cases of re-revascularization, among which 5 were caused by non-fatal AMI and 11 were caused by recurrent angina pectoris. The CHD group had 2 cases of re-revascularization, one because of nonfatal AMI and the other because of recurrent angina pectoris. The CHD group had 1 patient with ventricular fibrillation, who survived after the emergency rescue. The difference in all-cause mortality between the two groups was not statistically significant. The long-term rehospitalization and angina recurrence rates were significantly higher in the CHD-HT group than in the CHD group. The $>6-$ month clinical angina remission and in-stent restenosis rates did not statistically significant differ between the two groups (Table 3). The Kaplan-Meier survival analysis showed that the long-term event-free survival rates did not statistically significantly differ between the two groups $\left(\chi^{2}=1.152, P=0.2831\right.$, Fig. 1$)$.

Table 2 Characteristic of CAL of the two groups

\begin{tabular}{|c|c|c|c|c|c|c|c|c|}
\hline Group & $\begin{array}{l}\text { Single-vessel } \\
\text { lesion [n (\%)] }\end{array}$ & $\begin{array}{l}\text { Two-vessel } \\
\text { lesion [n (\%)] }\end{array}$ & $\begin{array}{l}\text { Thre } \\
\text { lesio }\end{array}$ & $\begin{array}{l}\text { e-vessel } \\
\text { [n }(\%)]\end{array}$ & $\begin{array}{l}\text { Left stem } \\
\text { artery } \\
\text { involved } \\
{[\mathrm{n}(\%)]}\end{array}$ & & $\begin{array}{l}\text { SYNTAX } \\
\text { integration }\end{array}$ & $\begin{array}{l}\mathrm{PCl} \text { therapy [n } \\
(\%)]\end{array}$ \\
\hline $\mathrm{A}(n=306)$ & $86(28.1)$ & $93(30.4)$ & 127 & (41.5) & 38 (12.4) & & $17.53 \pm 9.72$ & $210(68.6)$ \\
\hline $\mathrm{B}(n=156)$ & $46(29.5)$ & $57(36.5)$ & 53 & $(34.0)$ & $24(15.4)$ & & $15.21 \pm 10.92^{a}$ & $94(60.3)$ \\
\hline Group & $\begin{array}{l}\text { Lesion of target } \\
\text { vessel (vessels) }\end{array}$ & $\begin{array}{l}\text { Simple lesio } \\
(A+B 1)[n\end{array}$ & (\%)] & $\begin{array}{l}\text { Complex } \\
(B 2+C)\end{array}$ & $\begin{array}{l}\text { lesion } \\
\text { [n (\%)] }\end{array}$ & & $\begin{array}{l}\text { le-severe } \\
\text { ity [n (\%)] }\end{array}$ & $\begin{array}{l}\text { Middle-severe cal- } \\
\text { cification [n (\%)] }\end{array}$ \\
\hline $\mathrm{A}(n=306)$ & 240 & $100(41.7)$ & & $140(58.3)$ & & 21 & & $54(22.5)$ \\
\hline $\mathrm{B}(n=156)$ & 120 & $78(65)$ & & $42(35)^{b}$ & & 11 & 12 & $12(10)^{b}$ \\
\hline Group & $\begin{array}{l}\text { Diffused long } \\
\text { lesion [n (\%)] }\end{array}$ & $\begin{array}{l}\text { Average tar } \\
\text { vessels }\end{array}$ & & $\begin{array}{l}\text { Average } \\
\text { lesions (c }\end{array}$ & $\begin{array}{l}\text { target } \\
\text { cases) }\end{array}$ & & $\begin{array}{l}\text { ge stent } \\
\text { inted }\end{array}$ & $\begin{array}{l}\text { Left stem stent } \\
{[\mathrm{n}(\%)]}\end{array}$ \\
\hline $\mathrm{A}(n=306)$ & $98(40.8)$ & $1.36 \pm 0.57$ & & $1.51 \pm 0.6$ & & & $=0.93$ & $13(6.2)$ \\
\hline $\mathrm{B}(n=156)$ & $34(28.3)^{a}$ & $1.23 \pm 0.47$ & & $1.36 \pm 0.6$ & & & $=0.91^{a}$ & $6(6.4)$ \\
\hline
\end{tabular}

A: CHD-H group; B: CHD group

$\mathrm{PCl}$ percutaneous coronary intervention

Compared with the A group, ${ }^{\mathrm{a}} P<0.05,{ }^{\mathrm{b}} P<0.01$ 
Table 3 Post-PCI 2-year follow-up of the two groups

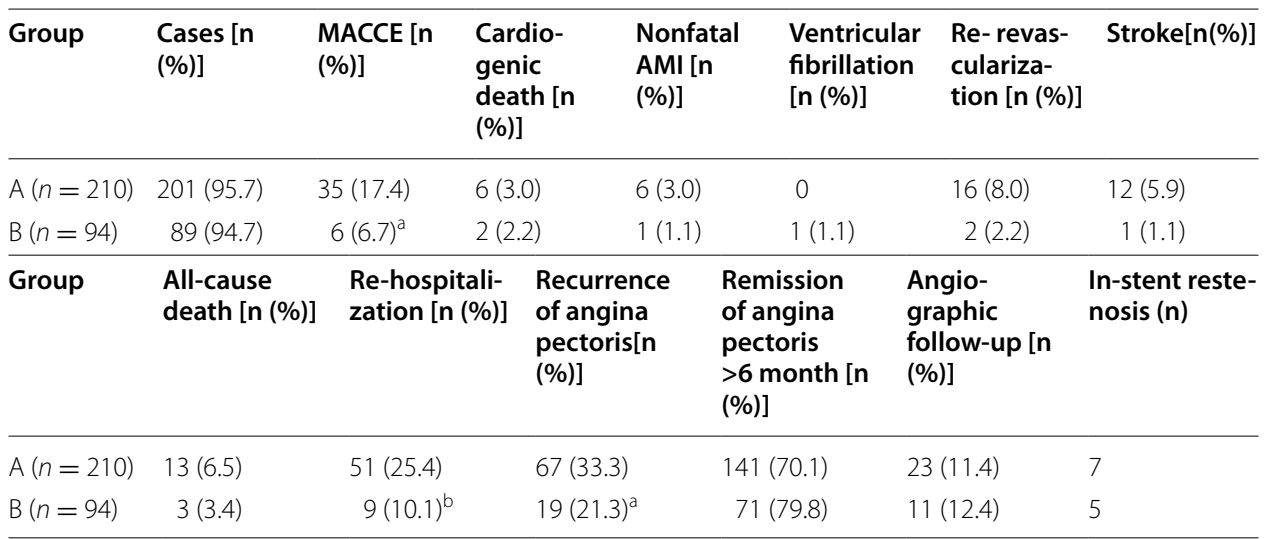

MACCE major adverse cardiac cerebrovascular events, $A M I$ acute myocardial infarction

Compared with the A group, ${ }^{\text {a }} P<0.05,{ }^{b} P<0.01$

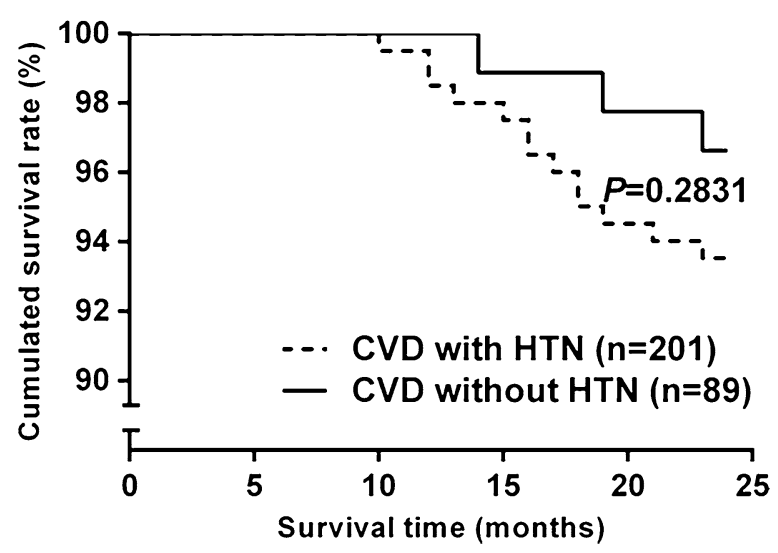

Fig. 1 Comparison of event-free survival curves of the two groups

\section{Multivariate logistic regression}

In the multivariate logistic regression analysis, age, male sex, hypertension, diabetes, hyperlipidemia, and previous histories of myocardial infarction and smoking were included as covariates into the model. The SS was calculated as a variable $(\geq 22$ was defined as 1 and $<22$ was defined as 0 ). The results showed that in the general population, the corrected age, sex, hypertension, diabetes, hyperlipidemia, and previous history of myocardial infarction were independent predictors of CHD complexities $(P<0.05$, Table 4).

Age-adjusted correlation analyses were performed to examine the relationship between systolic blood pressure levels and the SS in the overall population, and in the CHD-HT and CHD groups separately. The results showed that hypertension was significantly related to the SS and systolic blood pressures in the overall population $(P<0.05$, Tables 5, 6). 
Table 4 Multifactor logistic regression analysis of general population

\begin{tabular}{lrlrll}
\hline & B & SE & Wald & HR (95 \% Cl) & $P$ \\
\hline Age & 1.413 & 0.301 & 22.067 & $4.107(2.278-7.405)$ & 0.000 \\
Male & 0.856 & 0.292 & 8.600 & $2.355(1.328-4.174)$ & 0.003 \\
Hypertension & 0.872 & 0.309 & 7.964 & $2.392(1.305-4.384)$ & 0.005 \\
Diabetes & 0.895 & 0.289 & 9.596 & $2.446(1.389-4.308)$ & 0.002 \\
Hyperlipidemia & 0.915 & 0.285 & 10.309 & $2.497(1.428-4.365)$ & 0.001 \\
Previous myocardial infarction & 1.204 & 0.449 & 7.178 & $3.333(1.382-8.042)$ & 0.007 \\
Smoke & -0.513 & 0.298 & 2.959 & $0.599(0.334-1.074)$ & 0.085 \\
\hline
\end{tabular}

Table 5 Age-adjusted relations between blood pressure levels and syntax score

\begin{tabular}{lrlcl}
\hline Group & B & SE & HR (95 \% Cl) & P \\
\hline A $(n=306)$ & 0.201 & 0.025 & $3.630(0.042$ to 0.141$)$ & 0.000 \\
B $(n=156)$ & -0.006 & 0.073 & $-0.075(-0.150$ to 0.139$)$ & 0.325 \\
The whole population & 0.165 & 0.022 & $3.632(0.037$ to 0.123$)$ & 0.000 \\
\hline
\end{tabular}

Table 6 correlation analysis of SYNTAX integration and MACCE

\begin{tabular}{|c|c|c|c|c|c|c|c|c|}
\hline & \multicolumn{4}{|c|}{ Univariate analysis } & \multicolumn{4}{|c|}{ Multivariate analysis } \\
\hline & B & SE & $\mathrm{HR}(95 \% \mathrm{Cl})$ & $P$ & B & SE & $\mathrm{HR}(95 \% \mathrm{Cl})$ & $P$ \\
\hline MACCE & 6.366 & 1.542 & 3.877 (3.140 to 9.593) & 0.000 & 4.062 & 1.776 & 2.287 (0.572 to 7.552$)$ & 0.023 \\
\hline Cardiac death & 9.721 & 3.609 & 2.694 (2.629 to 16.813$)$ & 0.007 & 1.825 & 1.986 & $\begin{array}{l}0.366(-7.973 \text { to } \\
11.623)\end{array}$ & 0.715 \\
\hline Revascularization & 10.251 & 2.405 & $4.262(5.524$ to 14.977$)$ & 0.000 & 7.169 & 2.631 & 2.725 (2.000 to 12.338$)$ & 0.007 \\
\hline Nonfatal AMI & 3.368 & 2.823 & $\begin{array}{l}1.193(-2.189 \text { to } \\
8.925)\end{array}$ & 0.234 & & & & \\
\hline Stroke & 4.004 & 2.078 & $\begin{array}{l}1.927(-0.086 \text { to } \\
8.093)\end{array}$ & 0.055 & & & & \\
\hline All-cause mortality & 7.759 & 2.570 & 3.019 (2.709 to 12.809$)$ & 0.003 & 5.792 & 3.534 & $\begin{array}{l}1.639(-1.152 \text { to } \\
12.736)\end{array}$ & 0.102 \\
\hline
\end{tabular}

\section{Discussion}

Hypertension is known as a strong risk factor of coronary atherosclerosis. However, whether hypertension is a risk factor of complexity and severity of coronary atherosclerosis remains to be elucidated. In some studies, authors investigated the relationship between the prevalence, severity, and plaque characteristics of coronary atherosclerosis and blood pressure grade. The results of their studies strongly suggest that the incidence of coronary calcification was similarly high in hypertension and diabetes mellitus, and that coronary atherosclerosis shows a grade-response relationship according to hypertension grade (Graham et al. 2012; Grossman et al. 2013; Im et al. 2014; Tomizawa et al. 2015). In this study, the mean SS in the CHD-HT group was higher than that in the CHD group. The analysis of the characteristics of PCI target-vessel lesions revealed that the prevalences of complex, calcified, and diffused long lesions were significantly higher in the CHD-HT group than in the CHD group. The mean number of stent implantations 
was also significantly higher in the CHD-HT group than in the CHD group, suggesting that the CHD-HT patients had more-complex CAL.

Tanaka et al. (2013) found that among the risk factors of CHD, aging, male sex, and diabetes mellitus were identified as significant independent risk factors of the complexity of CAL. Other coronary risk factors such as hypertension, hypercholesterolemia, and smoking were not identified as significant independent risk factors. While the results of this study were not consistent with the results of their study, this study found that within the general population and the CHD-HT group, not only age, male sex, and diabetes exhibited significantly positive correlations with the SS, but also hypertension, hyperlipidemia, and previous history of myocardial infarction, indicating that hypertension, hyperlipidemia, and previous history of myocardial infarction, as well as age, sex, and diabetes, were independent predictors of the complexity of CAL.

Although the pathogeneses of $\mathrm{CHD}$ and hypertension were independent from each other, there existed mutual reinforcing interaction between the two diseases, the atherosclerosis process in CHD patients could be significantly accelerated owing to the presence of hypertension and the reduction in coronary reserve caused by hypertensive microvascular disease could aggravate the coronary arterial stenosis (Delles et al. 2012; Erbel et al. 2012; Juhola et al. 2013; Moges et al. 2014).

Studies have confirmed that hypertension was an independent risk factor of the occurrence and prognosis of CHD events (Makridakis and DiNicolantonio 2014; Nilsson and Cederholm, 2011; Zambon et al. 2014; Zanchetti 2014). In this study, the post-PCI 2-year follow-up results revealed that compared with the CHD group, although the incidence of MACCE (cardiac death, nonfatal myocardial infarction, re-revascularization, and stroke) between the two groups had no statistical significance, the incidence of overall MACCE was still significantly higher in the CHD-HT group than in the CHD group.

Some papers showed an association between coexistence of hypertension and diabetes and negative synergistic effect on SYNTAX score. It may be the diabetes and the hypertension were in the same stage, but there were not the serious symptom. Then the hypertension and diabetes were coexistence. Instead either of hypertension without diabetes or diabetes without hypertension were not associated with high SYNTAX score. These differences may be caused by: First, as mentioned above, different ethnic groups have different lifestyles, eating habits, geographical and cultural differences and other extrinsic factors. Secondly, CHD is multiple factor disease. In addition to the risk factors, the differences existed in gene in different ethnic. The Kaplan-Meier survival analysis revealed that the long-term event-free survival rates between the two groups had no significant difference, indicating that in addition to hypertension, blood glucose and blood lipid levels were also important factors of coronary events and prognosis and that the more-systematic medications of the post-PCI patients might play certain roles in improving the prognosis.

\section{Conclusions}

Arterial hypertension can be considered as a changeable risk factor for the complexity of coronary lesions in patients with ischemic heart disease, and the in-depth understanding of it, as well as the implementation of early therapeutic intervention, could delay CAL 


\section{progression in CHD-HT patients. Comprehensively controlling various risk factors were extremely important in CHD prevention and prognosis improvements.}

\section{Abbreviations}

CAL: coronary arterial lesions; CHD: coronary heart disease; MACCE: major adverse cardiac cerebrovascular events; SS: SYNTAX scores; PCl: percutaneous coronary intervention; LDL: low-density lipoprotein; MACCE: major adverse cardiac cerebrovascular events; AMI: acute myocardial infarction.

\section{Authors' contributions}

JX: conception and design and critical revision of the manuscript. JXZ: writing the manuscript. HZD, BWC, HLC: data collection and analysis and interpretation. All authors read and approved the final manuscript.

\section{Acknowledgements}

We appreciate all the colleagues who provided help in the Tianjin Chest Hospital.

\section{Competing interests}

The authors declare that they have no competing interests.

Received: 20 May 2016 Accepted: 14 July 2016

Published online: 29 July 2016

\section{References}

Delles C, Neisius U, Carty DM (2012) Proteomics in hypertension and other cardiovascular diseases. Ann Med 44:S55-S64 Erbel R, Lehmann N, Möhlenkamp S, Churzidse S, Bauer M, Kälsch H, Schmermund A, Moebus S, Stang A, Roggenbuck U, Bröcker-Preuss M, Dragano N, Weimar C, Siegrist J, Jöckel KH (2012) Subclinical coronary atherosclerosis predicts cardiovascular risk in different stages of hypertension: result of the Heinz Nixdorf Recall Study. Hypertension 59:44-53

Farooq V, Head SJ, Kappetein AP, Serruys PW (2014) Widening clinical applications of the SYNTAX Score. Heart 100:276-287

Figueiredo VN, Yugar-Toledo JC, Martins LC, Martins LB, de Faria AP, de Haro Moraes C, Sierra C, Coca A, Moreno H (2012) Vascular stiffness and endothelial dysfunction: correlations at different levels of blood pressure. Blood Press 21:31-38

Frohlich ED, Susic D (2007) Blood pressure, large arteries and atherosclerosis. Adv Cardiol 44:117-124

Graham G, Blaha MJ, Budoff MJ, Rivera JJ, Agatston A, Raggi P, Shaw LJ, Berman D, Rana JS, Callister T, Rumberger JA, Min J, Blumenthal RS, Nasir K (2012) Impact of coronary artery calcification on all-cause mortality in individuals with and without hypertension. Atherosclerosis 225:432-437

Grossman C, Shemesh J, Dovrish Z, Morag NK, Segev S, Grossman E (2013) Coronary artery calcification is associated with the development of hypertension. Am J Hypertens 26:13-19

Head SJ, Farooq V, Serruys PW, Kappetein AP (2014) The SYNTAX score and its clinical implications. Heart 100:169-177

Im TS, Chun EJ, Lee MS (2014) Grade-response relationship between blood pressure and severity of coronary atherosclerosis in asymptomatic adults: assessment with coronary CT angiography. Int J Cardiovasc Imaging 30:105-112

Iqbal J, Vergouwe Y, Bourantas CV, van Klaveren D, Zhang YJ, Campos CM, García-García HM, Morel MA, Valgimigli M, Windecker S, Steyerberg EW, Serruys PW (2014) Predicting 3-year mortality after percutaneous coronary intervention: updated logistic clinical SYNTAX score based on patient-level data from 7 contemporary stent trials. JACC Cardiovasc Interv 7:464-470

Juhola J, Magnussen CG, Berenson GS, Venn A, Burns TL, Sabin MA, Srinivasan SR, Daniels SR, Davis PH, Chen W, Kähönen M, Taittonen L, Urbina E, Viikari JS, Dwyer T, Raitakari OT, Juonala M (2013) Combined effects of child and adult elevated blood pressure on subclinical atherosclerosis: the International Childhood Cardiovascular Cohort Consortium. Circulation 128:217-224

Lawes CM, Bennett DA, Lewington S, Rodgers A (2002) Blood pressure and coronary heart disease: a review of the evidence. Semin Vasc Med 2:355-368

Makridakis S, DiNicolantonio JJ (2014) Hypertension: empirical evidence and implications in 2014. Open Heart 1:e000048

McInnes GT (1995) Hypertension and coronary artery disease: cause and effect. J Hypertens Suppl 13:S49-S56

Moges B, Amare B, Fantahun B, Kassu A (2014) High prevalence of overweight, obesity, and hypertension with increased risk to cardiovascular disorders among adults in northwest Ethiopia: a cross sectional study. BMC Cardiovasc Disord 14:155

Mohr FW, Morice MC, Kappetein AP, Feldman TE, Ståhle E, Colombo A, Mack MJ, Holmes DR Jr, Morel MA, Van Dyck N, Houle VM, Dawkins KD, Serruys PW (2013) Coronary artery bypass graft surgery versus percutaneous coronary intervention in patients with three-vessel disease and left main coronary disease: 5-year follow-up of the randomised, clinical SYNTAX trial. Lancet 381:629-638

Nilsson PM, Cederholm J (2011) Diabetes, hypertension, and outcome studies: overview 2010. Diabetes Care 34:S109-S113

Serruys PW, Onuma Y, Garg S, Sarno G, van den Brand M, Kappetein AP, Van Dyck N, Mack M, Holmes D, Feldman T, Morice MC, Colombo A, Bass E, Leadley K, Dawkins KD, van Es GA, Morel MA, Mohr FW (2009) Assessment of the SYNTAX score in the Syntax study. Euro Interv 5:50-56 
Sipahi I, Tuzcu EM, Schoenhagen P, Wolski KE, Nicholls SJ, Balog C, Crowe TD, Nissen SE (2006) Effects of normal, prehypertensive, and hypertensive blood pressure levels on progression of coronaryatherosclerosis. J Am Coll Cardiol 48:833-838

Sudano I, Roas S, Noll G (2011) Vascular abnormalities in essential hypertension. Curr Pharm Des 17:3039-3044

Tanaka T, Seto S, Yamamoto K, Kondo M, Otomo T (2013) An assessment of risk factors for the complexity of coronary artery disease using the SYNTAX score. Cardiovasc Interv Ther 28:16-21

Tomizawa N, Nojo T, Inoh S, Nakamura S (2015) Difference of coronary artery disease severity, extent and plaque characteristics between patients with hypertension, diabetes mellitus or dyslipidemia. Int J Cardiovasc Imaging $31: 205-212$

Turnbull F (2003) Effects of different blood-pressure-lowering regimens on major cardiovascular events: results of prospectively-designed overviews of randomised trials. Lancet 362:1527-1535

Zambon A, Arfè A, Corrao G, Zanchetti A (2014) Relationships of different types of event to cardiovascular death in trials of antihypertensive treatment: an aid to definition of total cardiovascular disease risk in hypertension. J Hypertens 32:495-508

Zanchetti A (2014) Predictive, mechanistic, and therapeutic studies on hypertensionand cardiovascular morbidity and mortality. J Hypertens 32:1549-1550

\section{Submit your manuscript to a SpringerOpen ${ }^{\circ}$} journal and benefit from:

- Convenient online submission

- Rigorous peer review

- Immediate publication on acceptance

- Open access: articles freely available online

- High visibility within the field

- Retaining the copyright to your article

Submit your next manuscript at $>$ springeropen.com 